\title{
Updating the Precise Gravity Network at the BIPM
}

\author{
Z. Jiang, E.F. Arias, L. Tisserand, K.U. Kessler-Schulz, H.R. Schulz, \\ V. Palinkas, C. Rothleitner, O. Francis, and M. Becker
}

\begin{abstract}
The goal of maintaining an accurate gravity network at the BIPM headquarters is twofold: firstly to support the International Comparison of Absolute Gravimeters (ICAG), and secondly to support the BIPM watt balance (WB) project, which aims at determining the Planck constant $h$ or realizing a future new definition of the kilogram based on a fixed value of $h$. In addition the absolute gravity measurements, Relative Gravity Campaign (RGC) is organized as part of each ICAG.

The BIPM gravity network is characterized by its small size, indoor laboratory conditions, three-dimensional structure, and large number of parallel absolute gravity determinations. Over the last 3 decades, repeated precise horizontal and vertical ties have been measured using relative and absolute gravimeters, and precision leveling has been undertaken regularly to monitor the deformation of the terrain. The ICAG is held every 4 years; the 8th ICAG took place in mid-2009 and for the first time, it was organized as a metrological key comparison as defined by the CIPM MRA. Its results will such constitute a precise and consistent gravity
\end{abstract}

Z. Jiang $(\bowtie) \cdot$ E.F. Arias $\bullet$ L. Tisserand International Bureau of Weights and Measures (BIPM), Pavillon de Breteuil 92312 SEVRES CEDEX, France e-mail: zjiang@bipm.org

K.U. Kessler-Schulz • H.R. Schulz

Angewandte Gravimetrie (AG), Rosengarten, Germany

V. Palinkas

Geodetic Observatory Pecny (GOP), Research Institute of Geodesy, Topography and Cartography, Ondrejov, Czech Republic

C. Rothleitner • O. Francis

University of Luxembourg (UL), Luxembourg, Luxembourg

M. Becker $(\square)$

Institute of Physical Geodesy, Darmstadt University of

Technology (IPGD), Darmstadt, Germany

e-mail: becker@ipg.tu-darmstadt.de 
reference system in SI units which can be used as the global basis for geodetic and geophysical observations. Additionally, to support the WB project, the network was extended to the BIPM WB laboratory.

In this paper, we briefly recall the background of the ICAG/RGC2009 and outline the new characteristics of the updated network, the organization and the performance of the measurements. Finally we present preliminary results from the RGC2009.

\subsection{Introduction}

Notation:

Gal $=1 \mathrm{~cm} \mathrm{~s}^{-2}$

g: Absolute gravity acceleration value in $\mu \mathrm{Gal}$ (minus a constant value of $980900000 \mu \mathrm{Gal}$ );

RG/AG: Relative/Absolute gravimeter;

$\boldsymbol{\delta} g$ : Difference of $g$ measured by RG;

$\boldsymbol{\delta} \boldsymbol{g} / \boldsymbol{\delta} \boldsymbol{H}$ : Vertical gravity gradient;

KC/PS: Key Comparison/Pilot Study [1, 2];

Site, station and point: A site is comprised of one or several stations located in an isolated indoor laboratory. The three sites at the BIPM headquarters used in ICAG2009 are: A, B and WB (Fig. 32.4); a station is comprised of 3-5 points vertically aligned and is marked by a benchmark (Figs. 32.2, 32.3 and 32.4); a point is the location at $30 \mathrm{~cm}, 90 \mathrm{~cm}, 130 \mathrm{~cm}, 155 \mathrm{~cm}$ or $170 \mathrm{~cm}$ vertically above the benchmark of a station (Fig. 32.1a).

Simple schedule: the basic RG measurement set designed for the $\mathrm{KC}$;

Full schedule: a strengthened RG measurement schedule designed for the PS with more redundant measurements and closure constraints;

WB schedule: additional RG measurements at the watt balance site.

\subsubsection{Background}

An International Comparison of Absolute Gravimeters (ICAG) takes place every 4 years at the BIPM headquarters in Sèvres, France. The 8th ICAG (2009) was organized in accordance with a proposal made at the 3 rd Joint Meeting of the Working Group on Gravimetry of the Consultative Committee for Mass (CCM WGG) and the SGCAG 2.1.1 of the International Association of Geodesy (IAG), held on 24 August 2007 [1, 3]; it was agreed that the main part of
ICAG2009 should be considered a key comparison (KC, CCM.G-K1 [2]) under the terms of the Mutual Recognition Arrangement of the International Committee for Weights and Measures (CIPM MRA, www.bipm.org/en/convention/mra). This decision constitutes an important step in accurate gravimetry applications as it means that the resulting ICAG2009, traceable to the International System of Units (SI), can be used as the global basis for geodesic and geophysical observations. Measurements not forming part of the $\mathrm{KC}$ itself were undertaken in the framework of a pilot study (PS). The associated RGC2009 was therefore adapted to better support the new functions of the ICAG [3] and the WB project. The result is an extended, updated and SI-traceable gravity network at the BIPM.

The technical specifications of the RGC2009 were discussed during two meetings of the steering committee held at the BIPM headquarters in Sèvres on 21 Nov. 2008 and in Prague on 11-12 May 2009. A number of essential points were agreed during these two meetings:

1. The main role of RGC2009 is to support the KC and PS of the ICAG2009; the results are the set of gravity distributions above the gravity stations (with their uncertainties) which allow the individual absolute determinations to be reduced to the same reference to permit their comparison.

2. The result of the RGC2009 should be independent of the absolute result of ICAG2009, i.e., the RGConly computation does not require calibration from the ICAG.

3. The data recording and submission should be fully digital.

4. The measurements should be made using at least 5 gravimeters following carefully designed schedules.

5. The measurements should be closely synchronized with the ICAG2009. 
a

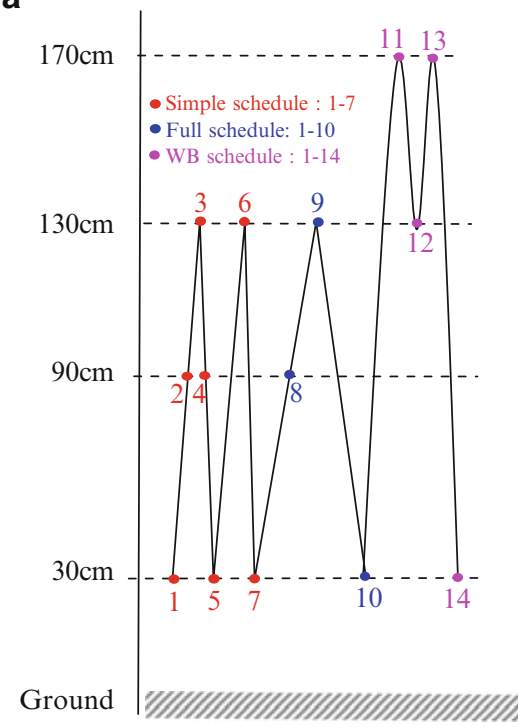

C

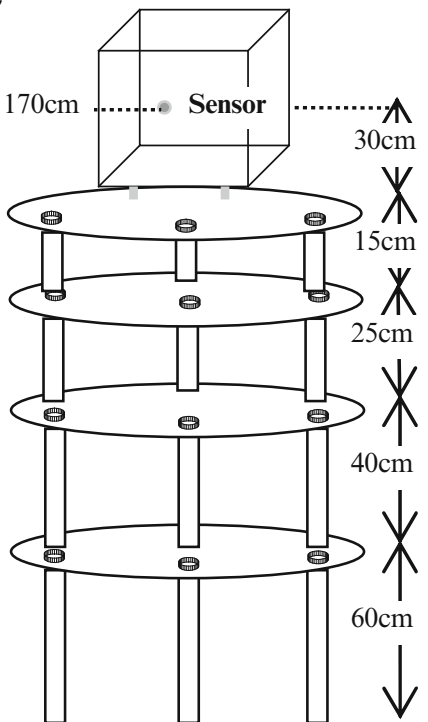

b

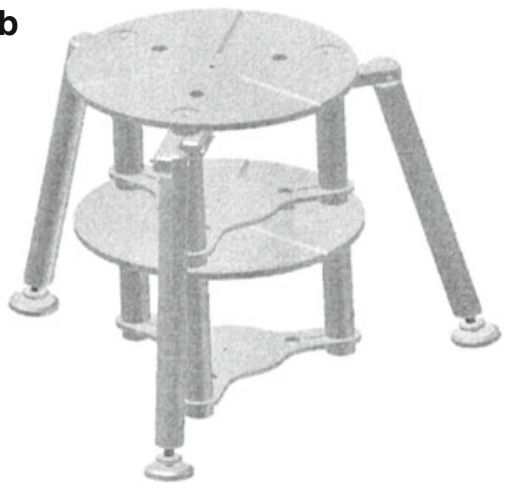

d

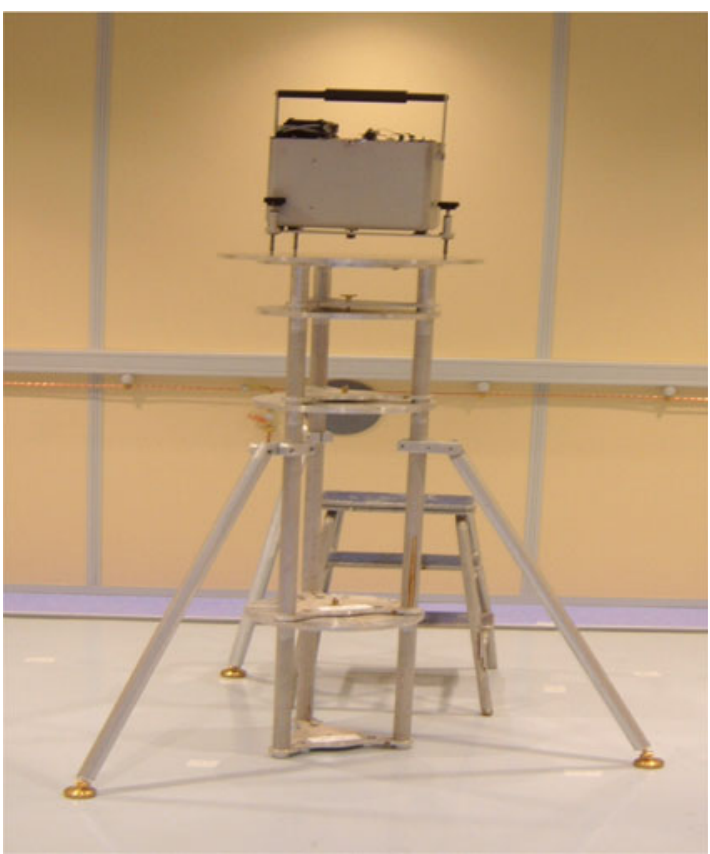

Fig. 32.1 (a) Vertical $\delta g$ measurements at a station following simple, full and WB schedules for a Scintrex CG gravimeter. (b) The BIPM tripods strengthened with removable legs for the measurements performed at heights of $155 \mathrm{~cm}$ and $170 \mathrm{~cm}$. (c) Set-up of the BIPM fixed-level tripod measurements using a Scintrex CG5 at a height of $170 \mathrm{~cm}$ at stations W1 and W2 (watt balance laboratory). (d) Set-up for measurements with a ZLS Burris gravimeter at a height of $155 \mathrm{~cm}$ at stations W1 and W2

6. Additional measurements should be organized in the framework of the BIPM watt balance (WB) project.

7. Measurements should be made using strengthened tripods to increase the stability (Fig. 32.1b) and to enable measurements at heights of $155 \mathrm{~cm}$ and $170 \mathrm{~cm}$ as required by the WB project.
Based on the above considerations and the experience gained in the previous RGCs [4, 5], it was decided that the best performing relative gravimeters should be used, for their advantages in calibration and digital data management. Nine selected Scintrex CG and ZLS BURRIS gravimeters were invited to participate. 
Table 32.1 List of the participants in the RGC2009

\begin{tabular}{lllll}
\hline No. & Institute/abbreviation & Gravimeter & No.\# & Operator \\
\hline 1 & BIPM & Scintrex CG5 & S348 & $\begin{array}{l}\text { L. Tisserand } \\
\text { Z. JANG }\end{array}$ \\
\hline $3 / 4$ & University of Luxembourg (UL) & Scintrex CG5 & $\begin{array}{l}\text { S008 } \\
\text { O. Francis } \\
\text { C. Rothleitner }\end{array}$ \\
\hline 5 & LNE-SYRTE (LS) & & S. Merlet \\
\hline $6 / 7$ & Bureau de Recherches Géologiques et Minières (BRGM) & Scintrex CG5 & S028 & P. Jousset \\
& & & S539 & D. Lequin \\
\hline 8 & Finnish Geodetic Institute (FGI) & & J. Mäkont \\
\hline 9 & Angewanden \\
\hline 10 & Gravimetrie (AG) & Scintrex CG5 & S052 & K.U. Schulz, H.R.Schulz \\
& RIGTC, Geodetic & ZLS & B025 & V. Palinkas \\
\hline
\end{tabular}

\subsubsection{Organization of RGC2009}

Unlike the previous ICAGs, the ICAG2009 consisted of two parts: a key comparison (KC) and a pilot study (PS) as described in detail in [1-3]. The measurement schedules and the data-processing strategy of the related "relative" campaign RGC2009 are described below. Matthias Becker (IPG DTU) and Zhiheng Jiang (BIPM) were charged with organizing the measurements and data processing.

\subsubsection{Participants of RGC2009}

Seven organizations with 9 gravimeters took part in RGC2009 (Table 32.1). The measurements were made during two periods: in August 2009 with 5 gravimeters (from BIPM, UL, AG and GOP) and in October 2009 with the other 4 gravimeters (from LS, BRGM and FGI). The fourth column in Table 32.1 (No.\#) shows the last three digits of the serial number of each gravimeter. Note that gravimeter No. 2 is not listed, as finally it was unable to participate.

\subsection{Design of the Vertical and Horizontal $\delta g$ Measurement Schedules}

The measurement schedule was designed to yield the lowest possible uncertainty in $\delta g$ under the BIPM laboratory conditions, given an achievable amount of work. The measurement scheme had a closure-based sequence with short and symmetrical time-distance intervals so as to minimize the influence of the uncertainties due to gravimeter zero-drift (reference point displacement with time), set-up of the gravimeters, and displacement and environmental influences. Level fixed tripods were used for the vertical $\delta g$ measurements to avoid errors in the height measurements. The main point of each station is defined at $90 \mathrm{~cm}$ vertically above the ground surface marker to reduce the near ground non-linear variation in $g$. The ZLS RGs are always set up to be oriented to the north. The RG sensor is vertically above the benchmark and close to the height of the defined point to minimize the eccentricity. A typical occupation takes about $5 \mathrm{~min}$, including setting up the gravimeter, allowing $30 \mathrm{~s}$ for stabilization, then making two readings averaged out of two samples of $100 \mathrm{~s}$ recordings separated by a $10 \mathrm{~s}$ pause. As described above, there were three categories of schedule; the simple schedule designed for the $\mathrm{KC}$, the full schedule for the PS and for further scientific studies where more redundant measurements and closure constraints are needed, and an additional WB schedule to investigate the local field in order to determine the $g$-value at the center of test mass of the WB. Raw digital recordings were reported to the BIPM, without any corrections such as for the Earth tide or zero-drift corrections.

In comparison with the previous RGCs, hold in 2001 [4] and 2005 [5], the main novel features of the RGC2009 are that:

1. Nine of the best performing gravimeters in Europe were invited to participate, including 7 Scintrex CG and 2 ZLS Burris. All have digital recording facility and owner calibration. The out-door sites $\mathrm{C} 1$ and C2 [5] were used to verify the owner calibrations. 
2. The number of the total occupations of a meter for RGC2005 was 157 which took 2-3 days. In 2009 there were 96 occupations in the simple schedule and 163 in the full schedule.

3. Instead of simply increasing the repeated measurements over the same ties, more geometry or closing conditions are designed in the full schedule, such as additional horizontal ties at heights of $30 \mathrm{~cm}$ and $130 \mathrm{~cm}$, producing a 3D grid instead of a simple horizontal net at $90 \mathrm{~cm}$ as before. This redundancy allows the constraints in the adjustment to be strengthened and gives more conditions to estimate the uncertainty and to improve the results of the ICAG, e.g., to directly compare the FG5 at $130 \mathrm{~cm}$ height.

4. A dedicated WB schedule was organized on the WB site with 101 additional occupations. The purpose of these measurements was to map the local $g$ distribution at the site of the WB before and after setting up the watt balance, using the so-called remove-restore technique.

Repeated precision leveling measurements have also been carried out between the benchmarks of all the stations. The leveling network is linked to the French national height reference (IGN69).

\subsubsection{Vertical $\delta g$ Ties}

Figure 32.1a illustrates the schedule of the vertical $\delta g$ measurements for the gradient determination at each station. These measurements were realized with the help of a set of fixed-level tripods. The simple-schedule included 7 occupations at each station, and the full schedule included 10 occupations. The measurements were made at the 8 stations $\mathrm{A}, \mathrm{B}, \mathrm{B} 1, \mathrm{~B} 2, \mathrm{~B} 3, \mathrm{~B} 4, \mathrm{~B} 5$ and $\mathrm{B} 6$, giving a total of 56 occupations in the simple schedule and 80 in the full one. In the WB schedule, additional points at $155 \mathrm{~cm}$ height for the ZLS meters and $170 \mathrm{~cm}$ height for the Scintrex meters were measured at the stations W1 and W2 so as to coincide with the reference height of the BIPM watt balance. Figures 32.1c, d show the set-up used for the vertical $\delta g$ measurements.

\subsubsection{Horizontal $\delta g$ Ties}

B site: Horizontal $\delta g$ 3D-grid measurements at site B were performed at a height of $90 \mathrm{~cm}$ for the simple schedule and at heights of $30 \mathrm{~cm}, 90 \mathrm{~cm}$ and $130 \mathrm{~cm}$ for the full schedule. The measurements followed two schemes as illustrated in Fig. 32.2: the "odd" scheme for the odd-numbered gravimeters $(1,3,5,7$ and 9 in Table 32.1) and the "even" scheme for the even-numbered gravimeters $(4,6,8$ and 10 in Table 32.1). There were 10 occupations at a height of $90 \mathrm{~cm}$ in the simple schedule and 10 occupations at each of $30 \mathrm{~cm}, 90 \mathrm{~cm}$ and $130 \mathrm{~cm}$ in the full schedule.

WB site: Horizontal $\delta g$ ties at the WB site were measured between $\mathrm{W} 1$ and $\mathrm{W} 2$ as illustrated in Fig. 32.3. W1 is the gravity station and $\mathrm{W} 2$ is the location of the BIPM watt balance for which the reference height will be about $1.5 \mathrm{~m}$ (not confirmed as yet). The gravity pillar $\mathrm{W} 1$ is founded $1.5 \mathrm{~m}$ deep in the

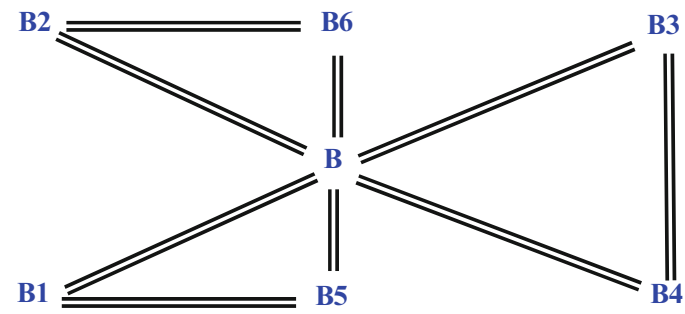

Odd schema: B-B1-B5-B-B2-B6-B-B3-B4-B for BIPMS348, UL-S008, LS-S105, BRGM-S539 and AG-B25

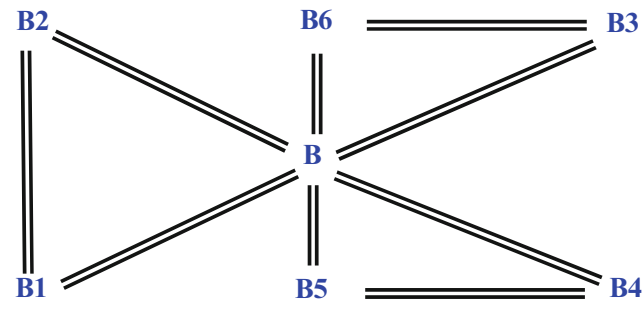

Even schema: B-B1-B2-B-B3-B6-B-B4-B5-B for UL-S010, BRGM-S028, FGI-S052 and GOP-B020

Fig. 32.2 Horizontal $\delta g$ grid measurement schedules at site B performed separately for heights of $30 \mathrm{~cm}, 90 \mathrm{~cm}$ and $130 \mathrm{~cm}$

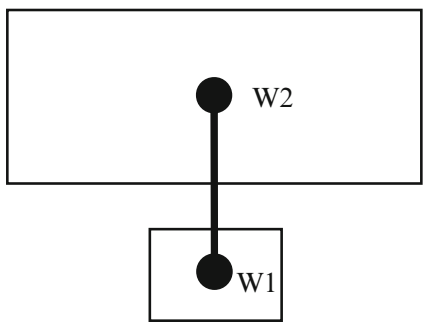

Fig. 32.3 Horizontal $\delta g$ tie measurements scheduled at site WB for heights of $30 \mathrm{~cm}, 90 \mathrm{~cm}, 130 \mathrm{~cm}, 155 \mathrm{~cm}$ and $170 \mathrm{~cm}$. $\mathrm{W} 1$ is the gravity station and W2 is the BIPM watt balance location 


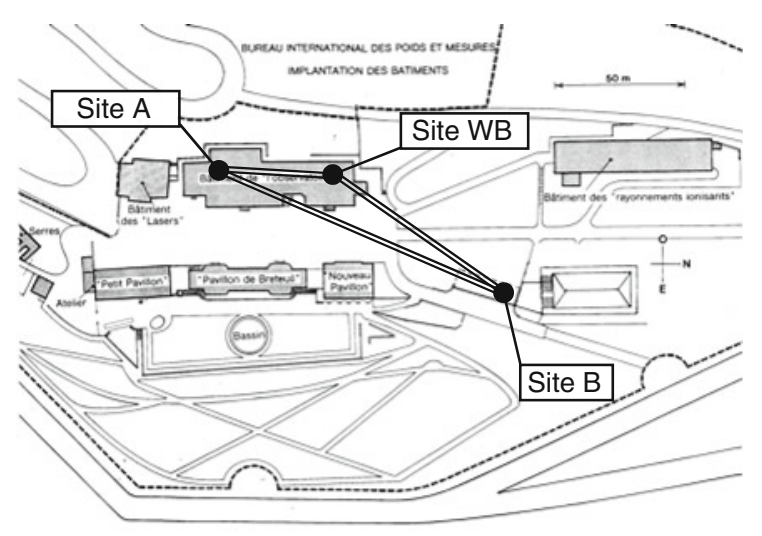

Fig. 32.4 Outdoor horizontal $\delta g$ measurements scheduled between the sites A, B and WB (simple schedule at a height of $90 \mathrm{~cm}$; full schedule at heights of $30 \mathrm{~cm}, 90 \mathrm{~cm}$ and $130 \mathrm{~cm}$

ground and has a top surface of $1.5 \mathrm{~m} \times 1.5 \mathrm{~m}$ which is $6 \mathrm{~cm}$ lower than the surrounding ground. The WB pillar also has a foundation of $1.5 \mathrm{~m}$ in the ground and a top surface of $4 \mathrm{~m} \times 2.5 \mathrm{~m}$ which is at the same level as the surrounding ground. There were 5 occupations at each station for each height of $30 \mathrm{~cm}, 90 \mathrm{~cm}$, $130 \mathrm{~cm}, 155 \mathrm{~cm}$ and $170 \mathrm{~cm}$.

Outdoor ties between the sites A, B and WB: Outdoor horizontal $\delta g$ measurements were scheduled between the sites A, B and WB as shown in Fig. 32.4 at a height of $90 \mathrm{~cm}$ for the simple schedule and at heights of $30 \mathrm{~cm}, 90 \mathrm{~cm}$ and $130 \mathrm{~cm}$ for the full schedule. There were 10 occupations for the simple schedule and 21 occupations for the full schedule with 7 occupations at each height.

W2 station: In order to set up a precise model of the local gravity field around the BIPM watt balance, a $3 \mathrm{D} \delta g$ grid was constructed based on measurements made at five horizontal levels at heights of $30 \mathrm{~cm}$, $90 \mathrm{~cm}, 130 \mathrm{~cm}, 155 \mathrm{~cm}$ and $170 \mathrm{~cm}$ above the station W2 (Fig. 32.5). The scheme consisted of four separated triangles, each triangle being closed at the point W2. To reduce the total number of measurements required, other ties, e.g., between W3, W5, W7 and W9, were not measured. Similarly, the heights of $155 \mathrm{~cm}$ and $170 \mathrm{~cm}$ were not measured by both of the models (Scintrex and ZLS). In total there were thus 52 occupations at heights of $30 \mathrm{~cm}, 90 \mathrm{~cm}$, $130 \mathrm{~cm}, 155 \mathrm{~cm}$ and $170 \mathrm{~cm}$ in the WB schedule.

WB site: To investigate the gravity variation in the WB laboratory, a grid consisting of the $\delta g$ profiles was measured. The horizontal $\delta g$ was measured at the

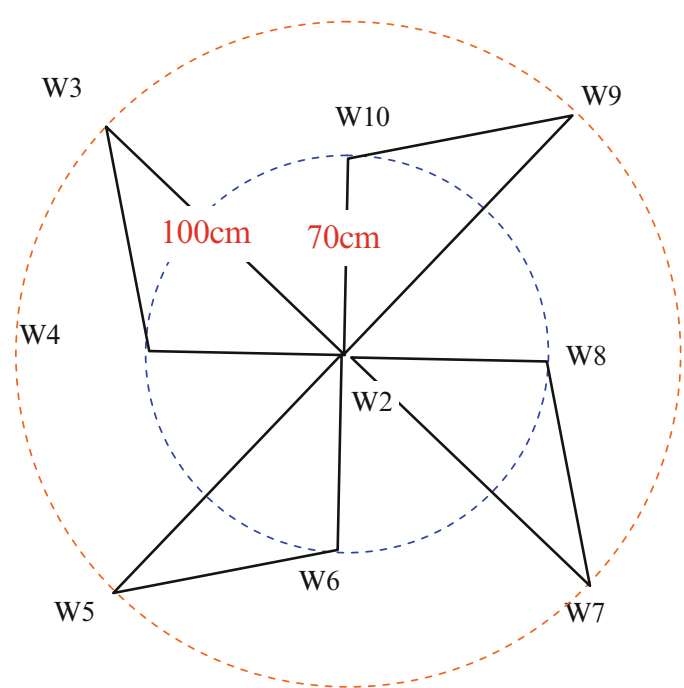

Fig. 32.5 Scheme of the horizontal $3 \mathrm{D} \delta g$ grid measurements scheduled at station W2 at heights of $30 \mathrm{~cm}, 90 \mathrm{~cm}, 130 \mathrm{~cm}$, $155 \mathrm{~cm}$ (for ZLS Burris) and $170 \mathrm{~cm}$ (for Scintrex CG5)

nodes of the grid with a cell - size of $2 \mathrm{~m} \times 2 \mathrm{~m}$, $130 \mathrm{~cm}$ above the ground. The grid consists of four independent closures as illustrated in Fig. 32.6. In total 42 occupations were organized for the WB schedule.

Table 32.2 displays the total number of occupations included in the different schedules. An adapted schedule was printed and distributed to the operators of the gravimeters. It was important that the schedules be tightly respected so that the designed uncertainty would be attained and all the results would be identifiable from the raw recordings. The latter is particularly important when identifying the causes of an outlying data point, which might arise due to measurement errors or simply typing errors in a point name. In total there were 96 and 163 occupations in the simple and full schedules, and 101 additional occupations in the WB schedule.

\subsection{Uncertainty Evaluation for a $\delta g$}

The measurement uncertainty was estimated assuming ideal indoor air-conditioned laboratory conditions, characterized by small values of $\delta g$, small and symmetric time intervals and short distances between the points, use of fixed-height tripods and respect of the carefully designed closure-based measurement schedules.

Table 32.3 lists the standard uncertainty budget of a $\delta g$ obtained during one measurement by a single RG $[1,5]$. Here "Eccentricity of gravimeter sensor" refers 
Fig. 32.6 The horizontal $\delta g$ grid measured in the WB schedule at the nodes of the grid on the WB site of which the cell surface is $2 \mathrm{~m} \times 2 \mathrm{~m}$ and $130 \mathrm{~cm}$ above the ground in the BIPM watt balance laboratory

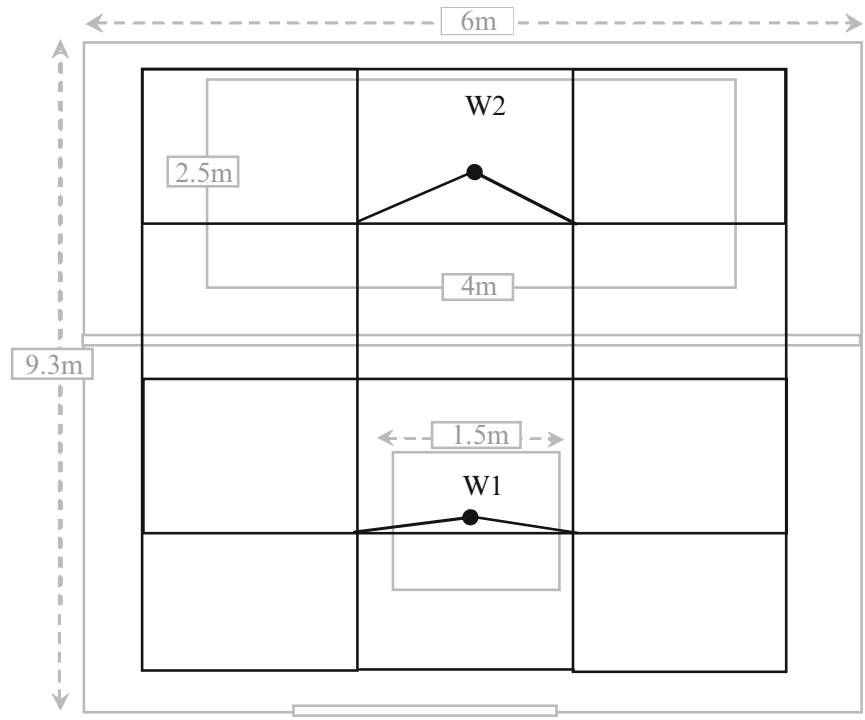

Table 32.2 Number of total occupations per gravimeter involved in each schedule

\begin{tabular}{llll}
\hline$\delta g$ & $\begin{array}{l}\text { Simple } \\
\text { schedule }\end{array}$ & $\begin{array}{l}\text { Full } \\
\text { schedule }\end{array}$ & $\begin{array}{l}\text { WB } \\
\text { schedule }\end{array}$ \\
\hline Vertical $\delta g$ & 70 & 100 & - \\
\hline Horizontal $\delta g$ at B & 9 & 27 & - \\
\hline $\begin{array}{l}\text { Horizontal } \delta g \text { between W1 and } \\
\text { W2 }\end{array}$ & 7 & 15 & 7 \\
\hline Horizontal $\delta g$ at W2 pillar & - & - & 52 \\
\hline $\begin{array}{l}\text { Horizontal } \delta g \text { grid at the WB } \\
\text { room }\end{array}$ & - & - & 42 \\
$\begin{array}{l}\text { Outdoor } \delta g \text { between A, B and } \\
\text { W1 }\end{array}$ & 10 & 21 & - \\
\hline \begin{tabular}{l} 
Total \\
\hline
\end{tabular} & 96 & 163 & 101 \\
\hline
\end{tabular}

Table 32.3 Estimated standard uncertainty of a $\delta g$ (gravimeter-measurement)

\begin{tabular}{lll}
\hline No. & Source of uncertainty & $\begin{array}{l}\text { Std. } \\
\text { Uncertainty } \\
/ \mu \mathrm{Gal}\end{array}$ \\
\hline 1 & Resolution of gravimeter readout & 1.0 \\
\hline 2 & Scale factor & 0.5 \\
\hline 3 & Feedback and non-linearity & 0.5 \\
\hline 5 & Un-leveling effect & 1.0 \\
\hline 6 & Environmental effects (e.g., Temperature) & 1.5 \\
\hline 7 & Transport/displacement & 1.0 \\
\hline 8 & Atmosphere pressure correction & 0.1 \\
\hline 9 & Eccentricity of gravimeter sensor & 1.5 \\
\hline 10 & Tidal corrections & 0.5 \\
\hline 11 & Zero-drift correction & 1.5 \\
\hline & TOTAL & 2.0 \\
\hline & & 3.8 \\
\hline
\end{tabular}

to the uncertainty due to the gravimeter sensor not being located exactly on the required point. The total combined standard uncertainty is about $4 \mu \mathrm{Gal}$. Assuming there are $\mathrm{M}$ RGs and each has $\mathrm{N}$ measurements, the uncertainty of the mean value of $\mathrm{M} \times \mathrm{N}$ measurements is $4.0 /(\mathrm{M} \times \mathrm{N})$, which is $\leq 2 \mu \mathrm{Gal}$ for $\mathrm{M} \times \mathrm{N} \geq 4$. In the simple schedule for the vertical gravity gradient measurements, $\mathrm{M} \times \mathrm{N}$ $\geq 16$, i.e., the uncertainty of the gradient correction $\leq 4.0 /(\mathrm{M} \times \mathrm{N}) / 0.4 \mathrm{~m} \leq 2.5 \mu \mathrm{Gal} / \mathrm{m}$.

\subsection{Preliminary Result}

Figure 32.7 shows histograms of the residuals of an adjustment for five of the gravimeters participating in the measurement campaign. The standard uncertainties of the ZLS Burris B020 and Scintrex CG5 S348 gravimeters are $1.3 \mu \mathrm{Gal}$ and $1.6 \mu \mathrm{Gal}$ respectively. Tables 32.4 and 32.5 give preliminary results. Table 32.4 presents the polynomial coefficients of the gradients and Table 32.5 the gravity differences at a height of $90 \mathrm{~cm}$ between the BIPM network stations.

\section{Conclusion}

ICAG2009 was the 8th in the series of International Comparisons of Absolute Gravimeters, but the first metrological key comparison, the results of which will be used for the BIPM watt balance project. The accompanying campaign of relative gravity 
Fig. 32.7 Histograms of the adjusted residuals for the gravimeters B020 and S348. The vertical axis in each case shows the residuals in $\mu \mathrm{Gal}$ and the horizontal axis is the frequency of a residual falling into the related interval

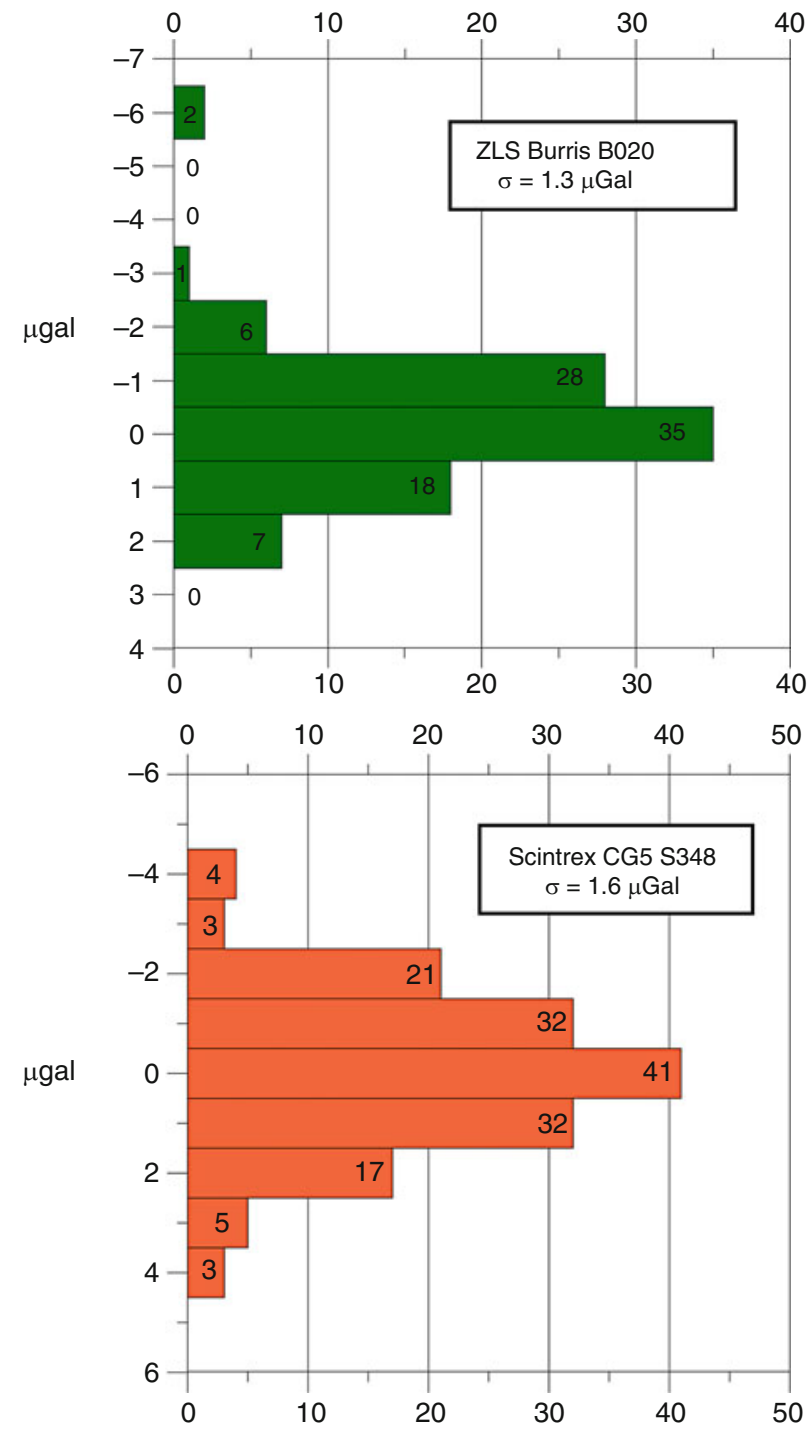

Table 32.4 Polynomial fitting of the gravity gradients, $\boldsymbol{g}(\mathrm{H})=\boldsymbol{a}+\boldsymbol{b} H+\boldsymbol{c H}$, with $H$ in $\mathrm{m}, \boldsymbol{a}$ in $\mu \mathrm{Gal}, \boldsymbol{b}$ in $\mu \mathrm{Gal} / \mathrm{m}$ and $\boldsymbol{c}$ in $\mu \mathrm{Gal} / \mathrm{m}^{2}$

\begin{tabular}{lccl}
\hline Station & $\boldsymbol{a}$ & $\boldsymbol{b}$ & $\boldsymbol{c}$ \\
\hline A & 25982.11 & -313.77 & 4.667 \\
\hline B & 28288.56 & -301.73 & 2.833 \\
B1 & 28275.37 & -296.70 & 6.000 \\
\hline B2 & 28256.38 & -291.97 & 5.667 \\
\hline B3 & 28273.67 & -304.53 & 4.333 \\
B4 & 28291.90 & -312.67 & 6.667 \\
B5 & 28289.87 & -302.27 & 3.417 \\
\hline B6 & 28264.56 & -299.53 & 5.583 \\
\hline W1 & 26714.51 & -269.17 & 0.417 \\
\hline W2 & 26635.89 & -271.13 & 6.083 \\
\hline
\end{tabular}

Table 32.5 Adjusted gravity differences in $\mu \mathrm{Gal}$ between the ICAG points at a height of $90 \mathrm{~cm}$

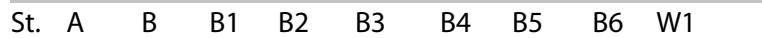

\begin{tabular}{|c|c|c|c|c|c|c|c|}
\hline A & 0.0 & & & & & & \\
\hline B & 2316 & 0.0 & & & & & \\
\hline B1 & 2310 & -6.1 & 0.0 & & & & \\
\hline B2 & 2295 & -21.1 & -15.0 & 0.0 & & & \\
\hline B3 & $2300-$ & -16.2 & -10.1 & 4.9 & 0.0 & & \\
\hline B4 & 2312 & -3.4 & 2.7 & 17.7 & 12.8 & 0.0 & \\
\hline B5 & 2317 & 1.3 & 7.4 & 22.4 & 17.5 & 4.7 & 0.0 \\
\hline B6 & $2296-$ & -19.8 & -13.7 & 1.3 & -3.6 & -16.4 & $-21.1 \quad 0.0$ \\
\hline W1 & $1769-1$ & 1546 & $5-1540-$ & -1525 & -1530 & $-1543-$ & $-1548-1527 \quad 0.0$ \\
\hline ריW & 93 & 22 & 61 & 601 & -160 & 615 & $624-160$ \\
\hline
\end{tabular}


measurements (RGC2009) was adapted correspondingly and the BIPM network was updated to follow the new developments. New features were that only selected relative gravimeters were used, the network was extended to the watt balance laboratory, new points were measured at heights of $150 \mathrm{~cm}$ and $170 \mathrm{~cm}$ and strengthened tripods were employed to improve the stability of the measurement set-up. The resulting network is a 3D-grid. In addition, new precision leveling was performed at all the gravity stations.

Measurement schedules employing two types of relative gravimeters were carefully designed to increase redundancy and constraints in order to reduce the uncertainty of the $\delta g$ and enable to study the performance of individual gravimeters.

The performance of ZLS and Scintrex gravimeters was compared and our preliminary analysis indicates that they agree very well within the estimated uncertainty. Detailed discussions will be given in a separate paper including the final results, the uncertainty analysis, comparisons with the results of the earlier ICAGs and that of the absolute determinations as well as the gravimeter behaviors etc.

Accurate knowledge of the BIPM gravity network provides a basis for monitoring the stability of the local gravity field at the BIPM.

\section{References}

1. BIPM, Technical Protocol of the 8th International Comparison of Absolute Gravimeters ICAG-2009

2. CIPM MRA Key Comparison CCM.G-K1. http://kcdb.bipm. org/appendixB/KCDB_ApB_result.asp?cmp_idy $=935 \& \mathrm{cmp}$ $\operatorname{cod}=\& \operatorname{search}=\& \mathrm{cmp} \_$cod_search $=\&$ page $=\&$ met_ idy $=$ $\&$ bra_idy $=\&$ epo_idy $=\& \mathrm{cmt} \_i d y=\& e t t \_i d y \_o r g=\& c o u$ $\operatorname{cod}=$

3. BIPM, 1st Circular letter about Relative Gravity Campaign 2009. ftp://tai.bipm.org/ICAG/2009/RGC/FirstLetter/

4. Vitushkin L, Becker M, Jiang Z, Francis O, van Dam TM, Faller J, Chartier J-M, Amalvict M, Bonvalot S, Debeglia N, Desogus S, Diament M, Dupont F, Falk R, Gabalda G, Gagnon CGL, Gattacceca T, Germak A, Hinderer J, Jamet O, Jeffries G, Käker R, Kopaev A, Liard J, Lindau A, Longuevergne L, Luck B, Maderasl EN, Mäkinen J, Meurers B, Mizushima S, Mrlina J, Newell D, Origlia C, Pujol ER, Reinhold A, Richard Ph, Robinson IA, Ruess D, Thies S, van Camp M, van Ruymbeke M, de Villalta Compagni MF, Williams S (2002) Results of the Sixth International Comparison of Absolute Gravimeters ICAG-2001. Metrologia 39:407-24

5. Jiang Z, Becker M, Francis O, Germak A, Palinkas V, Jousset P, Kostelecky J, Dupont F, Lee CW, Tsai CL, Falk R, Wilmes H, Kopaev A, Ruess D, Ullrich MC, Meurers B, Mrlina J, Deroussi S, Métivier L, Pajot G, Pereira Dos Santos F, van Ruymbeke M, Naslin S, Ferry M (2009) Relative Gravity Measurement Campaign during the 7th International Comparison of Absolute Gravimeters (2005). Metrologia 46:214-226 